\title{
Advances in Thiopurine Drug Delivery: The Current State-of-the-Art
}

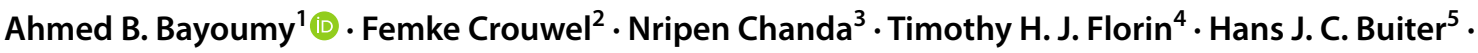 \\ Chris J. J. Mulder ${ }^{2} \cdot$ Nanne K. H. de Boer ${ }^{2}$
}

Accepted: 22 August 2021 / Published online: 6 September 2021

(c) The Author(s) 2021

\begin{abstract}
Thiopurines (mercaptopurine, azathioprine and thioguanine) are well-established maintenance treatments for a wide range of diseases such as leukemia, inflammatory bowel disease (IBD), systemic lupus erythematosus (SLE) and other inflammatory and autoimmune diseases in general. Worldwide, millions of patients are treated with thiopurines. The use of thiopurines has been limited because of off-target effects such as myelotoxicity and hepatotoxicity. Therefore, seeking methods to enhance target-based thiopurine-based treatment is relevant, combined with pharmacogenetic testing. Controlled-release formulations for thiopurines have been clinically tested and have shown promising outcomes in inflammatory bowel disease. Latest developments in nano-formulations for thiopurines have shown encouraging pre-clinical results, but further research and development are needed. This review provides an overview of novel drug delivery strategies for thiopurines, reviewing modified release formulations and with a focus on nano-based formulations.
\end{abstract}

Ahmed B. Bayoumy

a.b.bayoumy@amsterdamumc.nl

1 Faculty of Medicine, Amsterdam UMC, Location Academic Medical Centre, University of Amsterdam, Meibergdreef 9, 1105 AZ Amsterdam, The Netherlands

2 Department of Gastroenterology and Hepatology, AGEM Research Institute, Amsterdam University Medical Center, Location Vrije Universiteit Medical Center, Amsterdam, The Netherlands

3 Micro System Technology Laboratory, CSIR, Central Mechanical Engineering Research Institute, Durgapur, India

4 Inflammatory Bowel Diseases Group, Mater Research Institute, University of Queensland, Translational Research Institute, Woolloongabba, QLD, Australia

5 Department of Radiology and Nuclear Medicine, Amsterdam University Medical Center, Location Vrije Universiteit Medical Center, Amsterdam, The Netherlands

\section{Key Points}

Controlled-release formulations for thiopurines have been clinically tested and shown promising outcomes in inflammatory bowel disease.

Latest developments in nano-formulations for thiopurines have shown encouraging pre-clinical results, but further research and development is needed.

\section{Introduction}

In the 1950s, Gertrude Elion and George Hitchings developed thiopurines for the treatment of childhood leukemia, this revolutionized drug discovery. Historically, drug discovery was empirically based and often a result of a trial-anderror process. Elion and Hitchings rationally designed new molecules with specific molecular structures, which today is called rational drug design. For this, they were awarded the Noble Prize in Chemistry in 1988 [1]. The three thiopurines they discovered were thioguanine, mercaptopurine and azathioprine. These drugs have remained the cornerstone treatments for a wide range of diseases such as leukemia, organ rejection, inflammatory bowel disease (IBD) [2], 
systemic lupus erythematosus (SLE) and other inflammatory and autoimmune diseases in general. In this context, probably the most experience with thiopurines has been gained in the management of IBD, where thiopurines have been used since the early 1960s. Thiopurines are prodrugs that undergo extensive metabolism before they are converted into the active metabolites, 6-thioguanine nucleotides (6-TGN). This pool of 6-TGNs consists of both thioguanine ribonucleotides and deoxyribonucleotides. It has long been known that 6-TGNs, especially induced by higher dosages of thiopurines, can be incorporated into RNA and DNA as fraudulent bases through competing pathways. Incorporation into DNA results in a stop of replication by singlestrand breaks, crosslinking and sister chromatid exchange [3]. A more likely target of lower dose thiopurines is the Ras-related $\mathrm{C} 3$ botulinum toxin substrate 1 (Rac1) via ribonucleotide 6-thioguanine-triphosphate (6-TGTP) $[4,5]$. This 6-TGTP binds to Rac1 instead of GTP [6], and this complex induces apoptosis of activated T lymphocytes [4, 7]. Thiopurines, due to their chemical properties, are known for low solubility in water and varying rates of bioavailability [8]. In the last decade, various drug delivery formulations and approaches have been tested to improve the delivery of thiopurines for this reason. This review provides an overview of novel drug delivery strategies for thiopurines, reviewing modified release formulations, liposomal delivery systems and nano-formulations.

\section{Literature Search}

A literature search on PubMed was performed using the query mentioned in the appendix. The most recent search was performed up to August 2021. Furthermore, references were searched by hand for additional studies. Studies were included that investigated a drug delivery system for thiopurines (azathioprine, mercaptopurine, thioguanine or thiamiprine). Both clinical and non-clinical studies were included; reviews were excluded.

\section{Chemical and Pharmaceutical Properties of Thiopurines}

The thiopurines are structurally alike. They all consist of a thio-group and a purine, consisting of a pyrimidine-ring bonded to an imidazole-ring. Azathioprine contains an additional imidazole bonded to the sulfur group of mercaptopurine. In Fig. 1, the structural formulas with relevant chemical properties are shown for azathioprine, mercaptopurine, thioguanine and thiamiprine. Thiopurines can be subdivided into two classes (imidazole and non-imidazole thiopurines) and two groups (mercaptopurine and thioguanine groups).
It is essential to make these distinctions. An often forgotten thiopurine, and one deemed an 'impurity' in the synthesis of azathioprine [9], thiamiprine, is a prodrug form of thioguanine with an imidazole group attached. Although the literature about this drug is limited, preclinical studies have shown that it has stronger immunomodulating effects than azathioprine [10], which is consistent with it being a prodrug of thioguanine. The rationale behind the 1-methyl-4-nitro-imidazoyl derivative in azathioprine and thiamiprine is that these compounds were vulnerable to a nucleophilic attack between the sulfur on the purine and the methyl-nitroimidazole ring because of the ortho-nitro substituent [11]. This leads to the split between the purine and imidazole groups. It is thought that azathioprine partially evades first-pass metabolism because azathioprine is converted to mercaptopurine after liver metabolism $[12,13]$. In their early work, Elion et al. discovered that azathioprine and thiamiprine were as effective as mercaptopurine and thioguanine, but less toxic [11]. Furthermore, contemporary research has shown that a designer thiopurine analogue was less hepato- and myelotoxic and more effective in reducing inflammation than mercaptopurine [14]. Thus, thiopurines remain interesting compounds to be clinically tested for a wide range of diseases.

The chemical properties of thiopurines depend on essential parameters such as the partitioning coefficient $(\log P)$ and the water solubility. Marvin was used for the prediction and calculation of the chemical properties of the different thiopurines: Marvin 20.12, 2020-04-27, ChemAxon (www. chemaxon.com). The water solubility is influenced by the acid dissociation constant $\left(p K_{\mathrm{a}}\right)$. Thioguanine has $p K_{\mathrm{a}}$ values of 1.2 and 10.0, while mercaptopurine has $p K_{\mathrm{a}}$ values at 3.0 and 11.1. The $\operatorname{cog} P$ (at $\mathrm{pH} 7.4$ ) of thioguanine and mercaptopurine are -0.35 and -0.12 . Furthermore, the water solubility rates (at $\mathrm{pH}$ 7.4) of thioguanine and mercaptopurine are 0.05 and $0.09 \mathrm{mg} / \mathrm{ml}$. Hence, the solubility of both drugs is poor (the highest strength of a drug substance is soluble in $\leq 250 \mathrm{ml}$ aqueous media over the $\mathrm{pH}$ range of $1.0-6.8$ at $37 \pm 1^{\circ} \mathrm{C}$ ) according to the biopharmaceutical classification system (BCS) [15]. The bioavailability of thioguanine and mercaptopurine ranges from 5 to $42 \%[16,17]$. Thus, based on the solubility and bioavailability rates, thioguanine and mercaptopurine belong to BCS class IV drugs (poor solubility and poor permeability).

The poor water solubility of thiopurines remains a challenge for oral drug delivery. However, the magnitude of absorption is primarily determined by the extent of its unionized form at the site of absorption [18]. This explains why thiopurines can still be absorbed while the solubility is low in the gastrointestinal tract. More specifically, the absorption of thiopurine is controlled by the dissolution rate and the extent to which the drugs dissolve in the gastrointestinal tract [19]. As the $\mathrm{pH}$ in the stomach is low $(\sim \mathrm{pH} 1-2)$, it 
Advances in thiopurine drug delivery

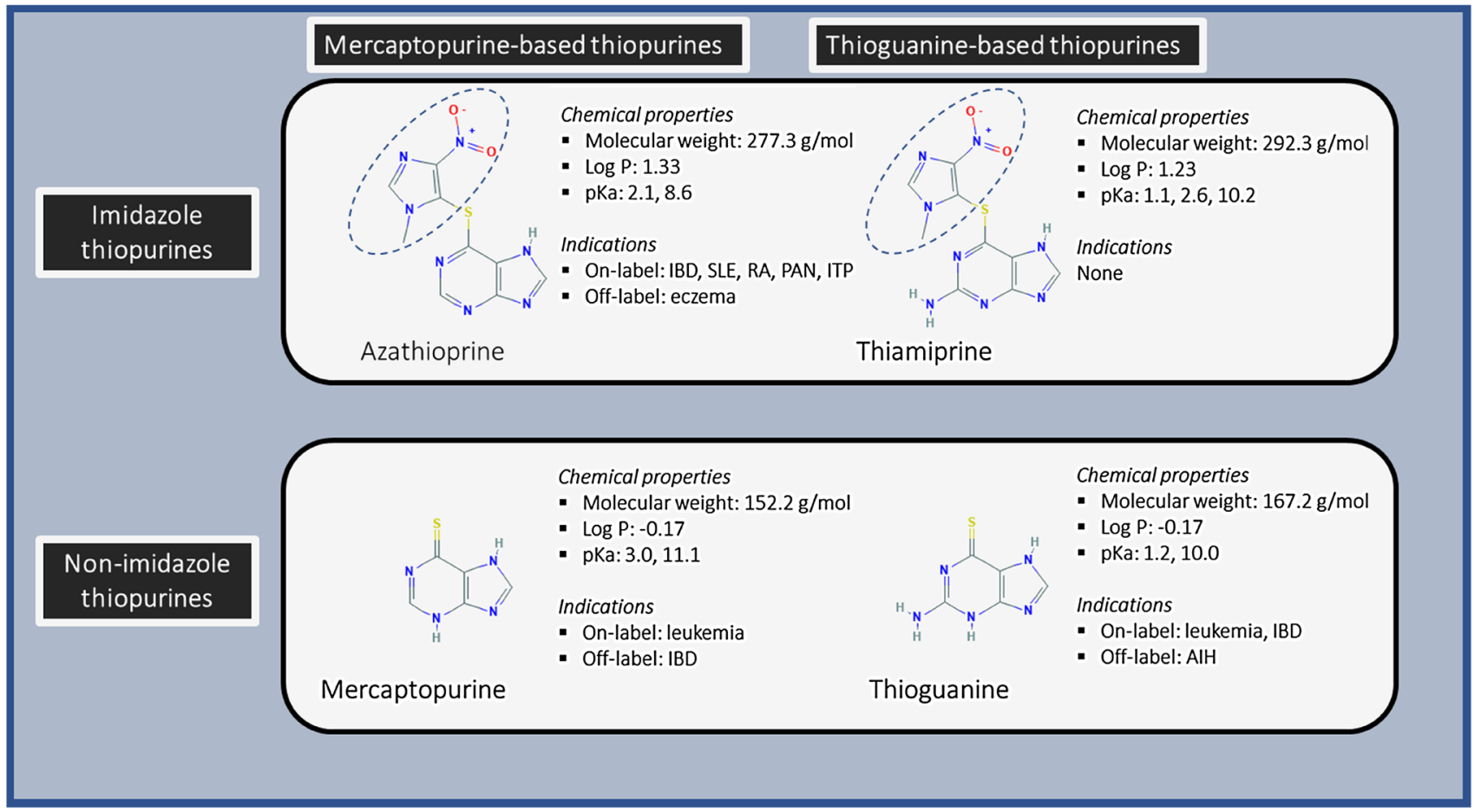

Fig. 1 Chemical properties of the different thiopurines. The thiopurines are divided into two classes (imidazole and non-imidazole thiopurines) and two groups (mercaptopurine and thioguanine groups). Highlighted in blue is the imidazole group. $I B D$ inflammatory bowel

is expected that the entire dosages of thioguanine and mercaptopurine can be dissolved rapidly in the gastric fluids. This is because most of thioguanine and mercaptopurine species are present in their protonated forms, which significantly increases their solubility $(\sim 1$ to $100 \mathrm{mg} / \mathrm{ml}$ at $\mathrm{pH}$ 1-2). However, further in the gastrointestinal tract, the $\mathrm{pH}$ levels increase, which causes a shift from protonated to unionized species of thiopurines in the small and large intestines where $\mathrm{pH}$ values are $>5.0[20,21]$. According to the $\mathrm{pH}$-partition hypothesis of drug absorption, the lipid bilayer of the gastrointestinal epithelium forms an impermeable barrier to protonated drugs, while the unionized forms are able to pass freely $[18,22]$.

\section{Pharmacogenetics}

Thiopurine methyltransferase (TPMT) and Nudix hydrolase 15 (NUDT15) are enzymes involved in thiopurine metabolism, and genetic polymorphisms in these enzymes are associated with thiopurine-related toxicities [23-25]. Testing of genetic polymorphisms has been implemented in clinical practice, especially in leukemia and IBD [26]. Moreover, novel data regarding thioguanine in treatment of childhood disease, $S L E$ systemic lupus erythematosus, $R A$ rheumatoid arthritis, $P A N$ polyarthritis nodosa, ITP immune-mediated thrombocytopenia, AIH autoimmune hepatitis

leukemia indicate that PGx testing is helpful to reduce thioguanine-related hepatic sinusoidal obstruction syndrome [27]. Furthermore, it has also been shown that TPMT geno-/ phenotype is significantly associated with TGN levels in thioguanine-treated IBD patients, but that TGN levels do not correlate with laboratory parameters [28]. The use of PGx is clinically important for thiopurine therapy, and it can be combined with novel drug delivery formulations to reduce toxicity.

\section{Pharmacokinetics}

In medical practice, thiopurines are in general delivered orally; however intravenous and rectal delivery has been described in the past [29]. The pharmacokinetics of thiopurine have been extensively studied, especially in patients with leukemia. Different dosages for the three thiopurines are commonly used. The oral dosages of thioguanine range between 5 and $40 \mathrm{mg} /$ day for IBD, while the dosages may go up three times higher for leukemia. The plasma halflife of thioguanine follows a bi-exponential figure, with an initial $t_{1 / 2}$ of $3.0 \mathrm{~h}$ and terminal $t_{1 / 2}$ of $5.9 \mathrm{~h}$. The 6 -thioguanine $N$ half-life of thioguanine varies from 4.4 to 9 days 
$[29,30]$. The daily dosage of mercaptopurine ranges from 1 to $2.5 \mathrm{mg} / \mathrm{kg}$. The plasma $t_{1 / 2}$ of mercaptopurine is $1.1 \mathrm{~h}$ [31], while the 6-TGN $t_{1 / 2}$ is approximately 5 days [32]. The daily azathioprine dosage ranges from 1 to $5 \mathrm{mg} / \mathrm{kg}$, with a serum $t_{1 / 2}$ of azathioprine of $0.2-0.5 \mathrm{~h}$ [33]. A meta-analysis showed that in IBD patients with 6-TGN cutoff levels $>235$ $\mathrm{pmol} / 8 \times 10^{8} \mathrm{RBC}$ and $250 \mathrm{pmol} / 8 \times 10^{8} \mathrm{RBC}$ had odd ratios for remission of OR 2.66 [95\% CI 1.94-3.66] and 4.71 [95\% CI 2.31-9.62] compared to below these cutoff levels [34]. Another meta-analysis also showed that higher 6-TGN levels were present in patients with leukopenia (mean difference $127.1 \mathrm{pmol} / 8 \times 10^{8} \mathrm{RBC}$ ) and gastrointestinal intolerance $\left(201.5 \mathrm{pmol} / 8 \times 10^{8} \mathrm{RBC}\right)$. Furthermore, 6-methylmercaptopurine ribonucleotides (6-MMPR) were significantly associated with hepatoxicity (mean difference $3241.2 \mathrm{pmol} / 8$ $\times 10^{8}$ RBC; OR 4.28 [95\% CI 3.20-5.71] [35]. Therefore, achieving adequate 6-TGN levels is clinically relevant for IBD patients. As the bioavailability of thiopurines is subject to high variability, drug delivery systems may aid in achieving more stable 6-TGN levels. This can in turn improve efficacy and reduce toxicity.

\subsection{Effects of Food Intake on Bioavailability of Thiopurines}

The effect of food has not been clarified sufficiently for thiopurine pro-drugs, but overall it appears that steadystate TGN drug levels are unaffected by concomitant ingestion of food. Concomitant food intake with oral thioguanine administration led to significantly decreased maximal plasma concentrations (Cmax) and decreased area-underthe-curve (AUC) values. That this did, however, not affect 6-TGN values 4 weeks after administration compared to fasting patients still requires further explanation [36]. The concomitant consumption of unprocessed cow's milk with mercaptopurine might also reduce the bioavailability of mercaptopurine, because unprocessed cow's milk contains high levels of xanthine oxidase [37]. Based on the chemical properties of the thiopurines at physiological conditions, it is to be expected that food and drugs affecting the gastric $\mathrm{pH}$ might affect the gastric solubility of thiopurines [36, 38].

\subsection{Drug-induced Effects on Thiopurine Metabolism}

The pharmacokinetics of thiopurines, not unexpectedly, can also be influenced by concomitant therapy with other drugs. The first step in the metabolism of mercaptopurine and its prodrug azathioprine is the conversion into 6-thioinosine monophosphate (6-TIMP) by hypoxanthine-guanine phosphoribosyl transferase (HPRT) [3] 6-TIMP is further metabolized by inosine monophosphate dehydrogenase (IMPDH), and in the end the pharmacologically active 6-TGNs are formed. Alternatively, mercaptopurine can be metabolized by thiopurine methyltransferase (TPMT) into the 6-methylmercaptopurines (6-MMP) pathways, associated with hepatotoxicity, or be catabolized by XO into 6-thiouric acid (6-TUA). The addition of allopurinol, a non-selective XO inhibitor, to azathioprine or mercaptopurine therapy leads to a rise in 6-TGN and a concomitant reduction in 6-MMPs [39]. Although the biological mechanism of this switch in preferential metabolism is not completely elucidated, it is suggested that TPMT is directly inhibited because of an increase in thioxanthine, which is a consequence of the inhibition of xanthine dehydrogenase by oxypurinol, the active metabolite of allopurinol [40]. While allopurinol only leads to the inhibition of reduced forms of $\mathrm{XO}$, febuxostat, a newer selective non-purine-based XO inhibitor, inhibits both oxidized and reduced forms and seems to have a greater potency to inhibit XO [41, 42]. It seems likely that co-administration of XO inhibitors and thiopurines causes a similar metabolic shift of thiopurine metabolism, and a case series demonstrated that concomitant use is indeed associated with TGNinduced myelosuppressive adverse events [42]. Sulfasalazine and other 5-aminosalicylic acid (5-ASA) derivates, used in gram doses to treat IBD, were shown to be potent in vitro inhibitors of recombinant human TPMT [43-45]. In vivo studies demonstrated increased levels of 6-TGN during concurrent therapy, especially with time-dependent 5-ASA formulations, and there has now been at least one report of a potentially serious drug interaction when these agents were administered to a patient who was also being treated with a standard doses of thiopurine drugs [43, 44, 46-52]. However, a randomized controlled trial involving $\mathrm{CD}$ patients who were randomly assigned to post-surgical treatment with azathioprine or mesalazine at all study visits found that TPMT activity did not differ between the two patient groups after 1 year follow-up [53]. Therefore, the mechanism by which thiopurines and 5-ASA derivates interact with each other is not completely understood. Still, physicians should be cautious when combining these drugs. Furosemide and to a lesser extent bendroflumethiazide and trichlormethiazide are in in vitro and ex vivo inhibitors of TPMT activity in red blood cells, although contradicting results, with elevated TPMT activities in subjects on diuretics, were reported in a population study [54-56]. The same study demonstrated that the use of non-steroidal anti-inflammatory drugs (NSAIDs) and antihypertensives seems to be associated with lower TPMT activity in red blood cells [56]. IMPDH is a target for drug interaction when azathioprine and ribavirin are used concomitantly because the inhibition of IMPDH by ribavirin leads to the conversion of 6-TIMP into 6-methylthioinosine monophosphate (6-MTIMP) via TPMT, and accumulation of 6-MTIMP is associated with myelotoxicity [57]. Unsurprisingly, a modest decrease in 6-TGN levels was observed during concomitant therapy, moderating azathioprine efficacy [58]. 


\subsection{Effects of the Microbiome on Thiopurines Metabolism}

Besides systemic conversion, thiopurines and especially thioguanine can also be prone to bacterial metabolism. It was demonstrated in vitro that representative gut bacteria were able to generate the pharmacologically active 6-TGN after incubation with thioguanine [59]. Dextran sulfate sodium (DSS)-treated HPRT-deficient mice had detectable fecal 6-TGN, suggesting a bacterial conversion of thioguanine into the active metabolites [60] given that host cells of HPRT-deficient mice cannot generate 6-TGN. Consistent with this, in vivo studies demonstrated an improvement of DSS-induced colitis in HPRT-deficient mice with oral thioguanine treatment [60]. When treating Winnie mice, a mouse with a spontaneous colitis due to a variant polymorphism in Muc2, with rectal thioguanine, a rapid and significant improvement of distal colitis was observed [60]. Following these observations of microbial conversion of thioguanine and their rectal benefit in Winnie with intact HPRT activity, a few IBD patients have been treated with rectally administered thioguanine. Systemic 6-TGN levels were low, and promising treatment responses were observed in an uncontrolled series [61]. Therefore, colonic delivery, via enemas, suppositories or oral tablets designed for that purpose, may provide additional benefit via microbial conversion of thioguanine to active drug and by actions at the level of the inflamed epithelium.

\section{Strategies for Thiopurine Drug Delivery}

There are various strategies to adjust or improve thiopurine drug delivery. This depends on the specific aims of these drug delivery strategies. These specific drug delivery aims include improved local delivery (e.g., intestinal drug exposure), reduced systemic exposure or reduced frequency of drug intake. This may result in improved efficacy, reduced toxicity and/or higher drug compliance. In this review, various strategies are discussed such as physical-chemical modifications, liposomes, polymer-based approaches, nanoparticles, controlled-release formulations and other strategies. A summary of studies performed that have investigated thiopurine drug delivery strategies are listed in Table 1.

\subsection{Physical-chemical Modifications}

By modifying physical or chemical properties of thiopurines, higher dissolution rates might be achieved, which might improve the bioavailability of thiopurines. Yang et al. [62] studied an amorphous complex of bismuth (III) bonded to three mercaptopurine molecules (Bi(mercaptopurine) ${ }_{3}$ $\left.\left.\left(\mathrm{NO}_{3}\right)_{2}\right] \mathrm{NO}_{3}\right)$. The solubility of the complex was increased compared to conventional mercaptopurine ( $1.2 \mathrm{vs} 0.14 \mathrm{mg} /$ $\mathrm{ml})$. In vitro, the complex showed strong inhibitory effects compared to conventional mercaptopurine on lung cancer cells. Another Chinese group [63] reported improved dissolution and bioavailability rates of co-crystalized mercaptopurine with isonicotinamide, a compound that has as the capability of inducing apoptosis in leukemia cell lines/models. Other studies also reported on the synthesis and structure determination of co-crystals of mercaptopurine [64, 65]. Thus, physicochemical modifications that increase solubility might be applied to advantage depending on where and how quickly the drug should be released for clinical ends.

\subsection{Nanomedicine Approaches}

Another promising strategy for thiopurine distribution is nano-based drug delivery. This field within drug delivery research has grown since the rise of nanotechnology. Nanoparticles are solid, colloidal particles that range from 10 to $1000 \mathrm{~nm}$ in size. Novel nano-based formulations have been developed and tested for thiopurines. These approaches include liposomal delivery, micelles, microspheres and metallic and polymeric based nanoparticles (see Fig. 2) [66-77].

\subsubsection{Liposomal Drug Delivery}

The discovery of liposomes, which are primarily composed of phospholipids, was attributed to Alec Bangham in 1961 [78]. Liposomes are closed spherical vesicles containing an aqueous core surrounded by mono- or bilayer membranes alternating with aqueous compartments. Liposomes can be formulated in sizes ranging from $30 \mathrm{~nm}$ to several micrometers in diameter. Important chemical properties are the size, composition, porosity and degradability of the liposomes [79]. Liposomes are biocompatible and are generally considered safe to use [80]. Furthermore, liposomes can be conjugated with various molecules that may increase specific targeting to the desired action site [81]. The liposomal delivery of mercaptopurine had already been studied in the mid-1970s. The results of these earlier studies were discouraging because of low encapsulation rates [82, 83]. More recently, liposomal drug delivery has been studied for azathioprine [84], thioguanine [85, 86] and mercaptopurine [87-90]. Taneja et al. [89] studied conventional and stealth liposomes in vitro and in albino rats. They found drug release rates after $6 \mathrm{~h}$ of the liposomal formulations of approximately $17 \%$, while free mercaptopurine had a drug release rate of $95 \%$ after $4 \mathrm{~h}$. Furthermore, they observed prolonged half-lives and increased AUC values for the liposomal formulations compared to free mercaptopurine. The most recent published study (2007) by Umrethia et al. [88] investigated the liposomal delivery of mercaptopurine using 


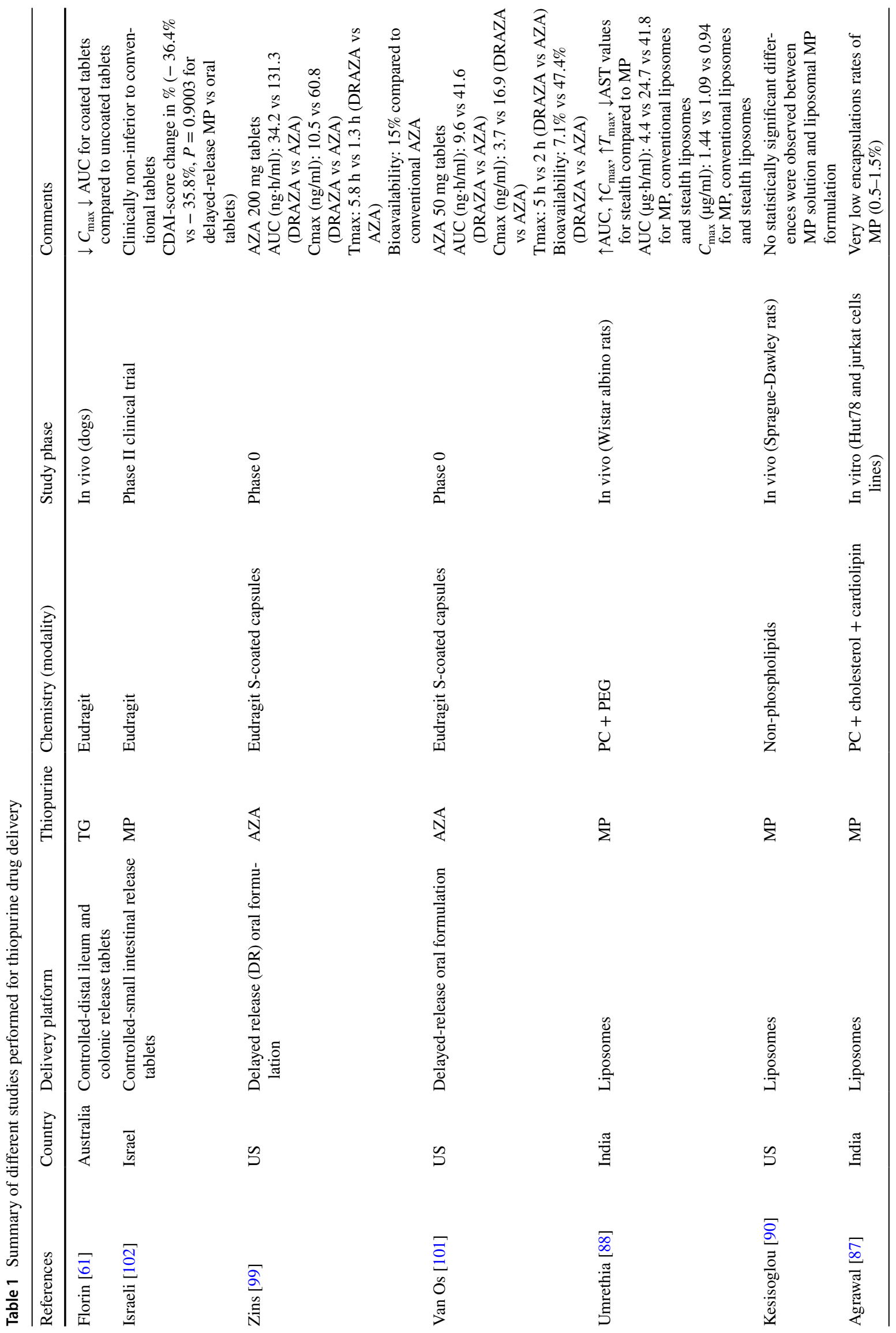




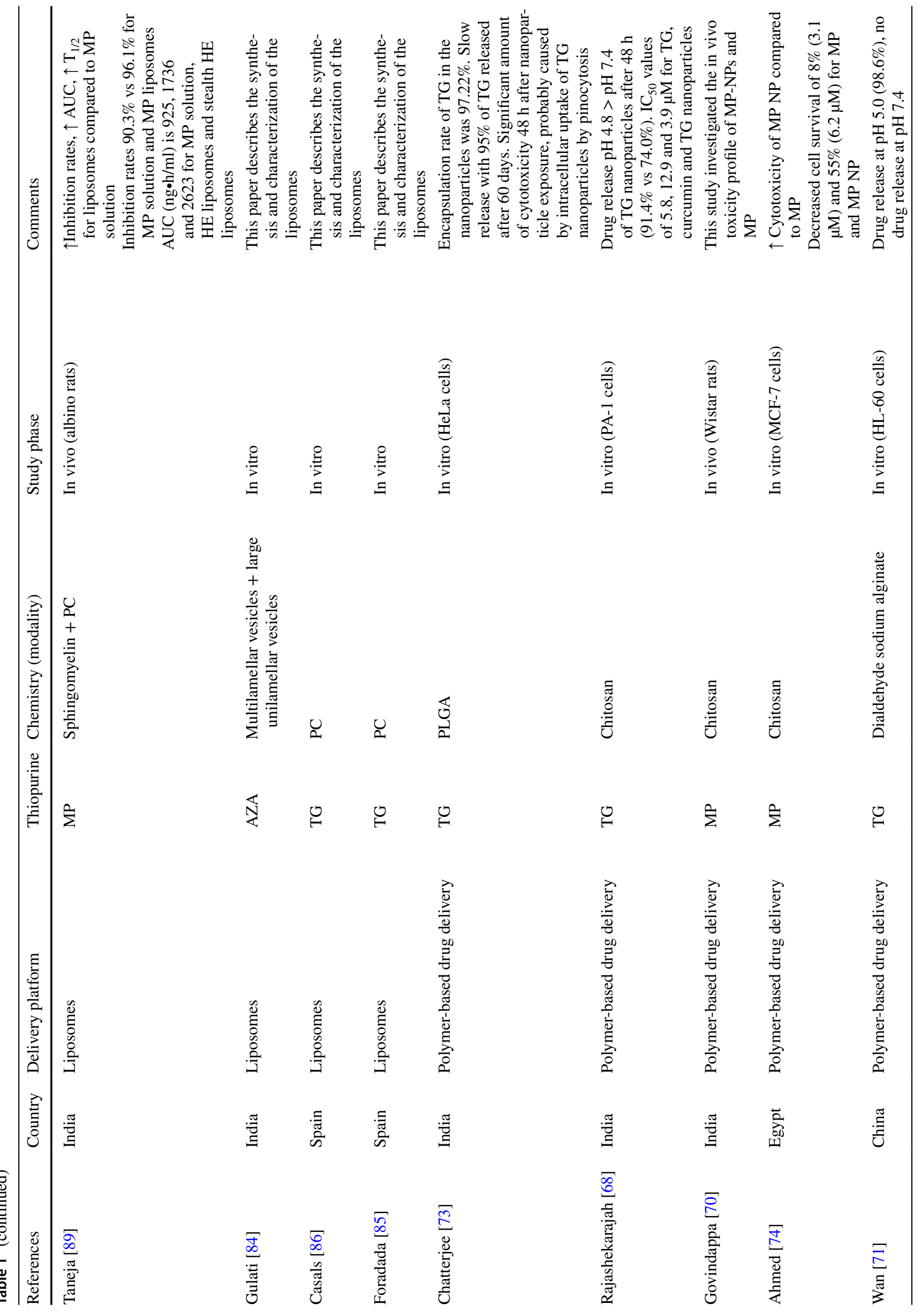




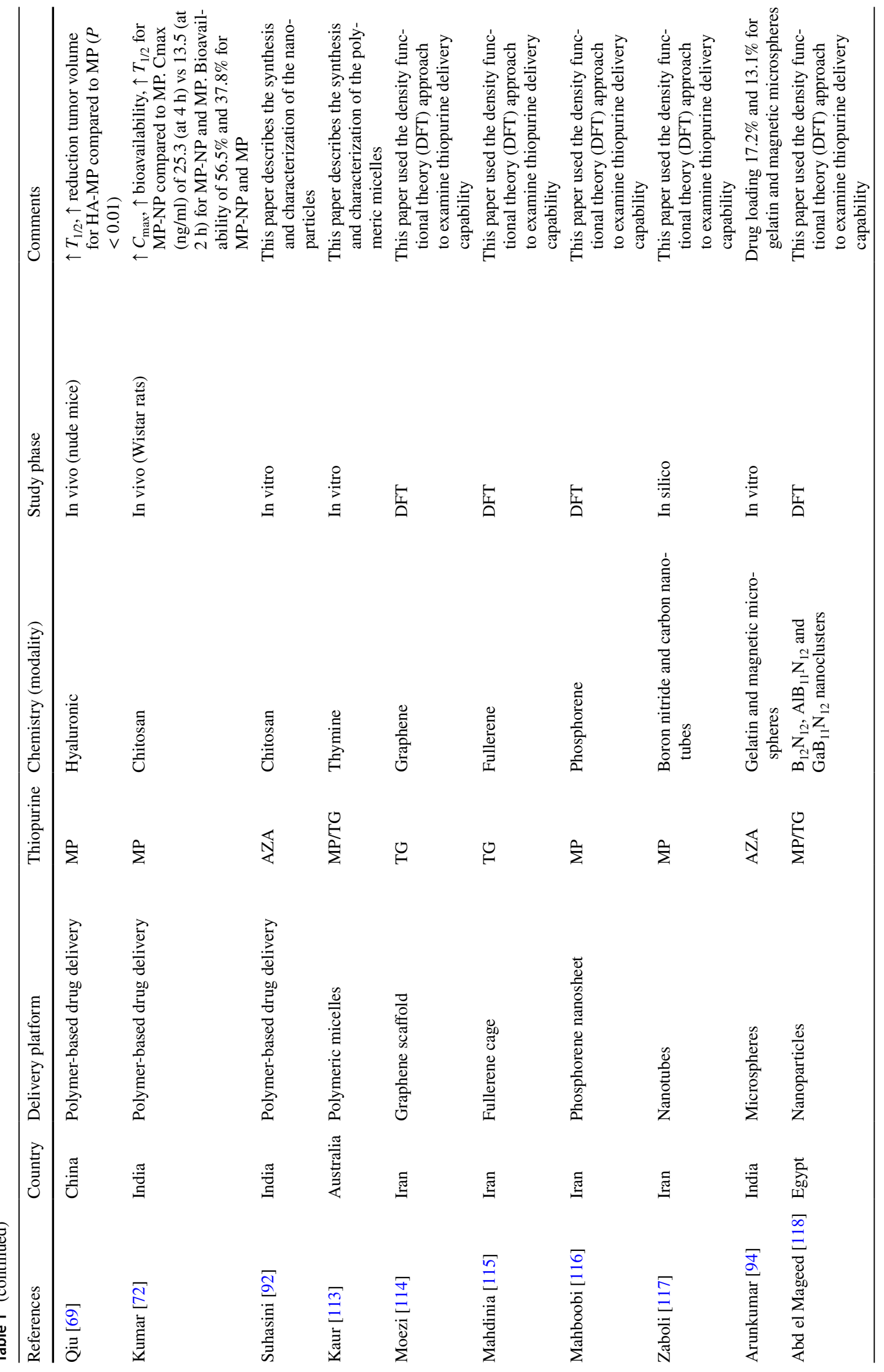




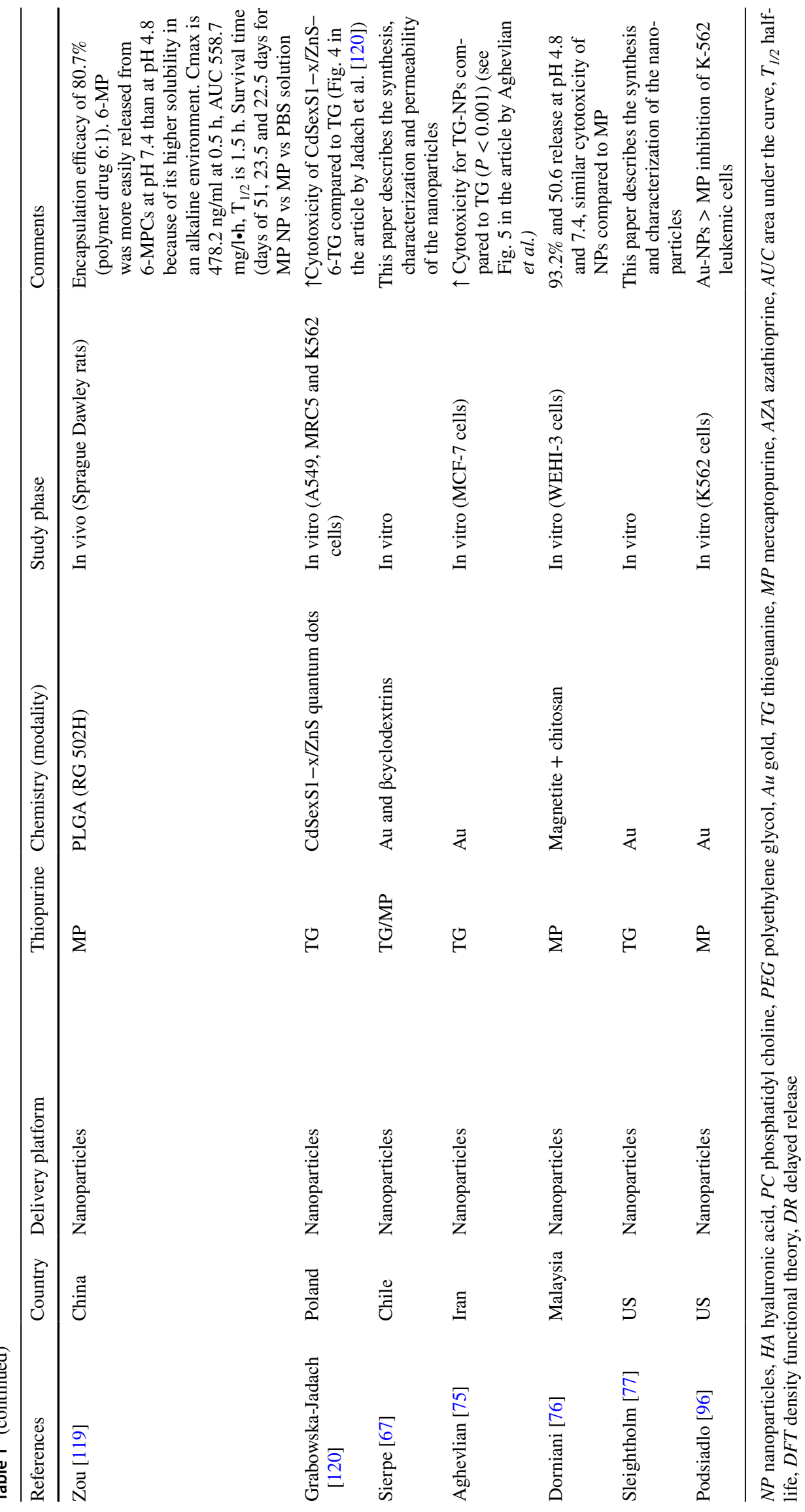


Advances in thiopurine drug delivery
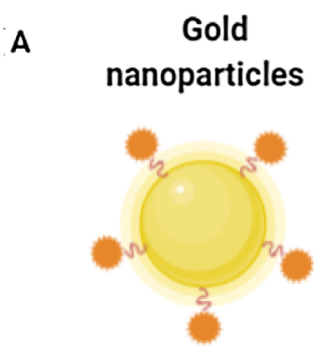

E

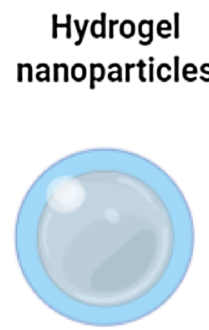

B
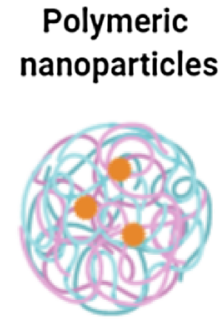

F
Microspheres

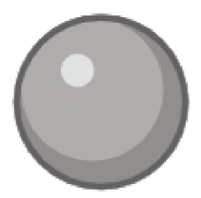

C
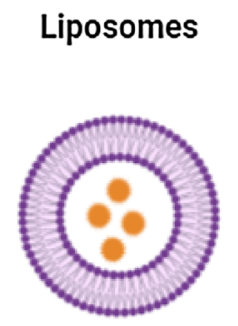

G

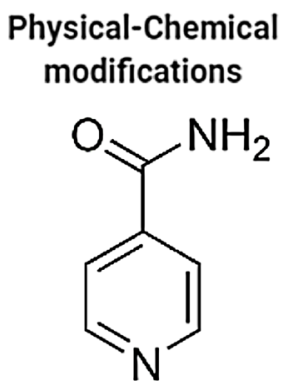

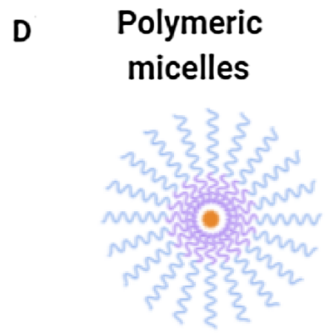

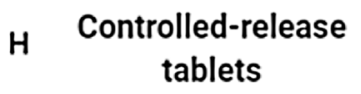

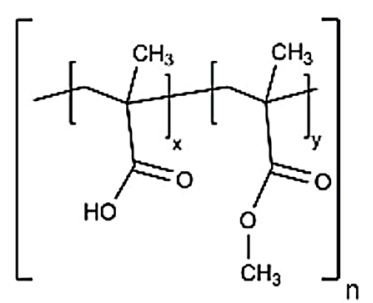

Fig. 2 Simplified overview of various delivery platforms that have been used for thiopurine drug delivery, created with BioRender.com

conventional and stealth liposomes. The stealth liposomes exhibited higher encapsulation rates $\left(E_{24} 94\right.$ vs $\left.33 \%\right)$ and higher AUC values (42 vs $25 \mu \mathrm{g} \mathrm{h} / \mathrm{ml}$ ) compared to conventional liposomes in a mouse model. The liposomal formulations showed favorable pharmacokinetics (higher AUC values, lower $C_{\max }$ values) compared to free mercaptopurine. Furthermore, they reported that the liposomal formulations had significantly less systemic exposure to various tissues such as the liver, kidney, heart, lungs and spleen compared to free mercaptopurine. The stealth liposomes had similar serum biochemical values compared to control, while the free mercaptopurine and conventional liposomes had significantly increased serum biochemical values compared to control. This study underlined that oral stealth liposomes could achieve higher bioavailability while potentially decreasing systemic side effects. Liposomal delivery seems to be especially useful for systemic diseases such as leukemia [91].

\subsubsection{Polymer-based Approaches}

Polymers are substances composed of macromolecules with many repeating subunits, which gives polymers the unique ability to be chemically modified to yield specific properties. An advantage of polymers is that they can be biodegradable and biocompatible. The most studied polymer for thiopurine delivery is chitosan. Thiopurine-loaded chitosan nanoparticles have been studied preclinically for thioguanine, azathioprine and mercaptopurine [68, 70, 72, 74, 92]. Chitosan nanoparticles display a $\mathrm{pH}$-dependent drug release profile due to the solubility of chitosan [93]. Other conjugated polymeric approaches have been described. These include thioguanine-dialdehyde sodium alginate nanoparticles [71], thioguanine-poly-lactic-coglycolic acid (PLGA) nanoparticles [73], azathioprinegelatin nanoparticles [94] and glutathione-sensitive hyaluronic acid-mercaptopurine nanoparticles [69].

Govindappa et al. [70] studied the toxicity of mercaptopurine-conjugated chitosan nanoparticles in an animal model. Both mercaptopurine and the mercaptopurine nanoparticles were categorized as category 4 (> 300-2000 $\mathrm{mg} / \mathrm{kg}$ bw) according to the Globally Harmonized Classification System. Furthermore, usage of low dosages $(15 \mathrm{mg} /$ $\mathrm{kg}$ ) of mercaptopurine and mercaptopurine nanoparticles did not lead to signs of myelotoxicity and hepatotoxicity. High dosages $(50 \mathrm{mg} / \mathrm{kg})$ led to a statistically significant reduction of hematological parameters compared to saline, low and mid $(30 \mathrm{mg} / \mathrm{kg})$ dose treatment, whereas biochemical parameters were significantly increased. These data suggested that mercaptopurine nanoparticles had a favorable toxicity profile compared to normal mercaptopurine drug formulations. Chatterjee et al. [73] investigated thioguanine conjugated PLGA nanoparticles. They obtained an encapsulation rate of $97 \%$ and a sustained drug release rate of $60-65 \%$ in the first 30 days. The nanoparticles exhibited cytotoxic properties in HeLa cells within $48 \mathrm{~h}$ of treatment, which was mediated by intracellular uptake of the nanoparticles. The high encapsulation rates and in vitro efficacy seem promising, but the 
polymer-based approaches have yet to reach the stage of clinical development.

\subsubsection{Metallic Nanoparticles}

Metallic nanoparticles are nanosized metals with a size ranging from 10 to $100 \mathrm{~nm}$. These metallic nanoparticles have unique features because they can be synthesized and modified in a way that allows them to bind with ligand, antibodies and drugs. The large surface-to-volume ratio of metallic nanoparticles allows them to bind many molecules [95]. A few studies have been performed with thiopurinecoated metallic nanoparticles. Thiopurine gold nanoparticles have been studied for thioguanine and mercaptopurine therapies $[67,77,96]$. The multivalent and highly adjustable surface architecture of gold nanoparticles offers the opportunity to incorporate multiple drugs on the surface of a single nanoparticle [97]. Podsiadlo et al. [96] found that mercaptopurine-gold nanoparticles were more effective in inhibiting human chronic myeloid leukemia cells than mercaptopurine alone. Aghevlian et al. [75] studied the effects of thioguanine-gold nanoparticles against breast cancer cells. They found significantly stronger inhibition of MCF-7 cancers by the thioguanine-gold nanoparticles compared to free thioguanine at higher concentrations $(6.2 \mu \mathrm{M})$. Furthermore, one study characterized mercaptopurine-coated magnetite nanoparticles as a controlled release delivery system in vitro [76]. Release rates of $93 \%$ and $51 \%$ were obtained at $\mathrm{pH}$ values of 4.8 and 7.4, respectively. The nanoparticle formulation showed sustained release kinetics, which may reduce systemic side effects. One disadvantage of metallic nanoparticles is that they might cause toxicity in the long term because of their size, as long-term exposure to metallic nanoparticles may affect cellular metabolism and energy homeostasis [98].

\subsection{Controlled-Release Drug Formulations}

The majority of thiopurines are administered by tablets via the oral route. The tablets used are known as 'immediaterelease' or 'conventional' drug delivery. There are circumstances in which the 'immediate release' is not desirable; therefore, manipulation of the release profile of the tablets is required. This is especially relevant in IBD, where inflammation is mainly located in the distal ileum and colon. The modified-release tablets refer to the modification of drug release from a dosage form to change the drug release rate or the localization of the release within the gastrointestinal tract. Attempts to develop modified-release or controlledrelease formulations have been tested in the past [99-101]. Israeli et al. [102] performed a phase II clinical trial of non-absorbable delayed-release tablets of mercaptopurine for Crohn's disease. For conventional oral mercaptopurine tablets, they found $C_{\max }, T_{\max }$ and AUC values of $82.1 \mathrm{ng} \mathrm{h} /$ $\mathrm{ml}$ (SD 28.7), 1.9 h (SD 1.1) and 216.1 ng/ml/h (SD 73.8), while for the delayed-release tablets these values were 6.1 $\mathrm{ng} \mathrm{h} / \mathrm{ml}, 9 \mathrm{~h}$ and $10.2 \mathrm{ng} \mathrm{H} / \mathrm{ml}$. Only one tablet formulation led to systematic release, while the other did not show any absorption at all. Thus, these delayed-release tablets demonstrated significantly lower or no systemic uptake suggestive of a local drug effect. Subsequently, this group performed a multi-center, double-blinded, double-dummy, two-arm phase II randomized non-inferiority trial for patients diagnosed with active Crohn's disease. The delayed-release tablets had significantly fewer adverse events than the conventional tablets $(67.5 \%$ vs $95.8 \%, P=0.0079)$. Higher clinical response rates after 8 weeks were obtained for the delayedrelease tablets versus conventional tablets $(48.3 \%$ vs $21.4 \%$, $P=0.01)$. They concluded that the delayed-release tablets were non-inferior to conventional mercaptopurine tablets. Their formulation was patented for the treatment of Crohn's disease (WO2015168448A1). This delayed-release formulation might also be interesting for thioguanine, which has similar physical-chemical properties to mercaptopurine and has also been proven safe and effective for Crohn's disease $[103,104]$. Recently, examples were given of direct extended release of thioguanine with enteric coating to prevent gastric dissolution and target the distal ileum and colon, the main sites of inflammation in IBD (WO2017054042A1) [61].

\section{Future Perspectives and Challenges}

In the past and present many different strategies have been proposed and tested for improvement of absorption and targeting the site of delivery of thiopurines. Drug delivery formulations have made it into clinical development; however, none has made it into clinical practice so far. Non-absorbable delayed-release tablets have been clinically non-inferior compared to conventional tablets for Crohn's disease and were associated with fewer adverse events due to decreased systemic uptake [102]. Furthermore, a phase 0 clinical trial was performed to investigate azathioprine delayed-release tablets, which showed significantly lower bioavailability and lower $C_{\max }$ compared to conventional azathioprine tablets $[99,101]$.

The latest developments in nano-formulations for thiopurines are promising because the first preclinical studies have provided encouraging results. Depending on the mechanism and properties of the nano-formulation, the design of these formulations could improve local delivery, reduce unwanted systemic side effects and offer comparable or improved efficacy at a lower concentration compared to conventional formulations. Local drug delivery is highly desirable in local bowel diseases such as IBD [105]. The disease localization should dictate the necessity for maximal intestinal drug 
exposure, whereas systemic exposure should be minimalized to prevent systemic side effects [106]. Given the potential additional mode of intestinal conversion of thioguanine to 6-TGN, local delivery becomes even more attractive [107, 108]. However, systemic diseases such as leukemia will always require adequate systemic drug levels [109]. Sustained or controlled release profiles of nano-formulations might achieve these adequate systemic levels while reducing side effects, as demonstrated in the previously discussed studies [70, 76, 88]. However, studies in humans have yet to be performed. Ideally, the sustained release formulation is able to decrease high toxic peak concentrations while still achieving adequate therapeutic concentrations. Another possible advantage of sustained release formulations is the reduction of the frequency of oral tablet intake. The translation from preclinical to clinical development has challenges to be resolved. Most studies are ex vivo and have focused on the potential to improve drug delivery $[110,111]$. Both the safety and efficacy of nano-formulations need to be clear to allow clinical development to progress. Another important issue is the potential of large-scale production of these nano-formulations. This might be very costly, and therefore it would not be cost-effective to use those drug delivery systems in daily practice [112].

\section{Conclusion}

Thiopurines are useful treatments in a wide range of diseases. The solubility of thiopurines is low, and the bioavailability of these drugs varies. The use of thiopurines has also been limited because of systemic side effects such as myelotoxicity and hepatotoxicity. Therefore, there is a need for novel drug delivery development approaches to improve targeted therapy and reduce side effects for millions of patients worldwide, especially those suffering from IBD. Delayed-release tablets are in clinical development, and preclinical data of nano-formulations show promising results. The combination of novel drug delivery formulations and adequate pharmacogenetic testing might improve patients' benefit in the future.

\section{Appendix}

\section{Search Query}

\section{PubMed}

("drug delivery systems"[MeSH Terms] OR ("drug"[All Fields] AND "delivery"[All Fields] AND "systems"[All
Fields]) OR "drug delivery systems"[All Fields] OR ("drug"[All Fields] AND "delivery"[All Fields]) OR "drug delivery"[All Fields] OR ("nano"[Journal] OR "nano"[All Fields]) OR ("liposomalization"[All Fields] OR "liposomalized"[All Fields] OR "liposomally"[All Fields] OR "liposome s"[All Fields] OR "liposomes"[Pharmacological Action] OR "liposomes"[MeSH Terms] OR "liposomes"[All Fields] OR "liposomal"[All Fields] OR "liposome"[All Fields] OR "liposomic"[All Fields] OR "liposomized"[All Fields]) OR ("polymer s"[All Fields] OR "polymers"[MeSH Terms] OR "polymers"[All Fields] OR "polymer"[All Fields]) OR ("nanoparticle s"[All Fields] OR "nanoparticles"[MeSH Terms] OR "nanoparticles"[All Fields] OR "nanoparticle"[All Fields]) OR ("micell"[All Fields] OR "micellation"[All Fields] OR "micelle s"[All Fields] OR "micelles"[MeSH Terms] OR "micelles"[All Fields] OR "micelle"[All Fields] OR "micellization"[All Fields] OR "micellized"[All Fields] OR "micellizing"[All Fields] OR "micells"[All Fields]) OR ("microsphere s"[All Fields] OR "microspheres"[MeSH Terms] OR "microspheres"[All Fields] OR "microsphere"[All Fields] OR "microspheric"[All Fields] OR "microspherical"[All Fields]) OR "Controlled-release"[All Fields]) AND ("thiopurine"[All Fields] OR "thiopurines"[All Fields] OR "azathioprin"[All Fields] OR "azathioprine"[MeSH Terms] OR "azathioprine"[All Fields] OR "thioguanine"[MeSH Terms] OR "thioguanine"[All Fields] OR "thioguanines"[All Fields] OR "mercaptopurine"[MeSH Terms] OR "mercaptopurine"[All Fields] OR "mercaptopurines"[All Fields] OR "thiamiprine"[Supplementary Concept] OR "thiamiprine"[All Fields]).

\section{Declarations}

Funding No source of funding.

Conflict of interest $\mathrm{AB}$ Bayoumy, F Crouwel, N Chanda and HJC Buiter have nothing to disclose. THJ Florin is a director of an Australian startup company ProdrugXtend Pty Ltd, which owns a PCT relating to thiopurines. CJJ Mulder has served as a consultant and principal investigator for HLW Pharma BV, Douglas Pharma and Arega. NKH de Boer has served as a speaker for AbbVie and MSD and has served as consultant and principal investigator for TEVA Pharma BV and Takeda. He has received a (unrestricted) research grant from Dr. Falk, TEVA Pharma BV, MLDS and Takeda, all outside the submitted work.

Ethics Approval Not applicable.

Consent to participate Not applicable.

Consent for publication Not applicable.

Availability of data and material Not applicable.

Code availability Not applicable. 
Authors' contributions $\mathrm{AB}$ Bayoumy performed the literature search, wrote the manuscript, and created the artwork and the table. F Crouwel reviewed the manuscript and wrote the Drug-induced effects on thiopurine metabolism section. CJJ Mulder, NKH de Boer, HJC Buiter, THJ Florin and N Chanda critically reviewed the manuscript.

\section{Acknowledgments Not applicable.}

Open Access This article is licensed under a Creative Commons Attribution-NonCommercial 4.0 International License, which permits any non-commercial use, sharing, adaptation, distribution and reproduction in any medium or format, as long as you give appropriate credit to the original author(s) and the source, provide a link to the Creative Commons licence, and indicate if changes were made. The images or other third party material in this article are included in the article's Creative Commons licence, unless indicated otherwise in a credit line to the material. If material is not included in the article's Creative Commons licence and your intended use is not permitted by statutory regulation or exceeds the permitted use, you will need to obtain permission directly from the copyright holder. To view a copy of this licence, visit http://creativecommons.org/licenses/by-nc/4.0/.

\section{References}

1. Elion GB. The purine path to chemotherapy (Nobel Lecture). Angew Chem Int Ed Engl. 1989;28(7):870-8.

2. Bayoumy AB, de Boer NKH, Mulder CJJ. Management of Crohn disease. JAMA. 2021;325(17):1793-4.

3. Bayoumy AB, Simsek M, Seinen ML, et al. The continuous rediscovery and the benefit-risk ratio of thioguanine, a comprehensive review. Expert Opin Drug Metab Toxicol. 2020;16:1-13.

4. Tiede I, Fritz G, Strand S, et al. CD28-dependent Rac1 activation is the molecular target of azathioprine in primary human CD4+ T lymphocytes. J Clin Invest. 2003;111(8):1133-45.

5. Quéméneur L, Gerland LM, Flacher M, Ffrench M, Revillard JP, Genestier L. Differential control of cell cycle, proliferation, and survival of primary $\mathrm{T}$ lymphocytes by purine and pyrimidine nucleotides. J Immunol. 2003;170(10):4986-95.

6. Neurath MF, Kiesslich R, Teichgräber U, et al. 6-Thioguanosine diphosphate and triphosphate levels in red blood cells and response to azathioprine therapy in Crohn's disease. Clin Gastroenterol Hepatol. 2005;3(10):1007-14.

7. Poppe D, Tiede I, Fritz G, et al. Azathioprine suppresses ezrinradixin-moesin-dependent $T$ cell-APC conjugation through inhibition of Vav guanosine exchange activity on Rac proteins. $\mathrm{J}$ Immunol. 2006;176(1):640-51.

8. Friedman AB, Sparrow MP, Gibson PR. Thiopurines; azathioprine, mercaptopurine and thioguanine. In: Parnham MJ, editor. Compendium of inflammatory diseases. Basel: Springer; 2016. p. 1-12.

9. Aleksandrova EV, Kochergin PM. Methods of synthesis and properties of S-substituted 6-thiopurines (review). Pharm Chem J. 2013;46(10):612-21.

10. Kochergin PM, Aleksandrova EV, Tolvinskaya LS, et al. The synthesis and immunotropic activity of a new azathioprine analog2-amino-6-(1-ethyl-2-methyl-4-nitroimidazolyl-5-mercapto) purine. Pharm Chem J. 2000;34(11):579-81.

11. Elion GB. The quest for a cure. Annu Rev Pharmacol Toxicol. 1993;33(1):1-25.

12. Kurowski V, Iven H. Plasma concentrations and organ distribution of thiopurines after oral application of azathioprine in mice. Cancer Chemother Pharmacol. 1991;28(1):7-14.
13. Van Asseldonk DP, de Boer NK, Peters GJ, Veldkamp AI, Mulder CJ, Van Bodegraven AA. On therapeutic drug monitoring of thiopurines in inflammatory bowel disease; pharmacology, pharmacogenomics, drug intolerance and clinical relevance. Curr Drug Metab. 2009;10(9):981-97.

14. Atreya I, Diall A, Dvorsky R, et al. Designer thiopurine-analogues for optimised immunosuppression in inflammatory bowel diseases. J Crohns Colitis. 2016;10(10):1132-43.

15. Yu LX, Amidon GL, Polli JE, et al. Biopharmaceutics classification system: the scientific basis for biowaiver extensions. Pharm Res. 2002;19(7):921-5.

16. Zimm S, Collins JM, Riccardi R, et al. Variable bioavailability of oral mercaptopurine. Is maintenance chemotherapy in acute lymphoblastic leukemia being optimally delivered? N Engl J Med. 1983;308(17):1005-9.

17. Deibert P, Dilger K, Fischer C, et al. High variation of tioguanine absorption in patients with chronic active Crohn's disease. Aliment Pharmacol Ther. 2003;18(2):183-9.

18. Hogben CA, Schanker LS, Tocco DJ, Brodie BB. Absorption of drugs from the stomach. II. The human. J Pharmacol Exp Ther. 1957;120(4):540-5.

19. Granero GE, Ramachandran C, Amidon GL. Gastrointestinal dissolution and absorption of drugs. In: Drug bioavailability. StatPearls; 2003. p. 189-214.

20. Nugent SG, Kumar D, Rampton DS, Evans DF. Intestinal luminal $\mathrm{pH}$ in inflammatory bowel disease: possible determinants and implications for therapy with aminosalicylates and other drugs. Gut. 2001;48(4):571-7.

21. Fallingborg J, Christensen LA, Jacobsen BA, Rasmussen SN. Very low intraluminal colonic $\mathrm{pH}$ in patients with active ulcerative colitis. Dig Dis Sci. 1993;38(11):1989-93.

22. Shore PA, Brodie BB, Hogben CA. The gastric secretion of drugs: a $\mathrm{pH}$ partition hypothesis. J Pharmacol Exp Ther. 1957;119(3):361-9.

23. Moriyama T, Nishii R, Perez-Andreu V, et al. NUDT15 polymorphisms alter thiopurine metabolism and hematopoietic toxicity. Nat Genet. 2016;48(4):367-73.

24. Coenen MJ, de Jong DJ, van Marrewijk CJ, et al. Identification of patients with variants in TPMT and dose reduction reduces hematologic events during thiopurine treatment of inflammatory bowel disease. Gastroenterology. 2015;149(4):907-917.e907.

25. Chen ZY, Zhu YH, Zhou LY, et al. Association between genetic polymorphisms of metabolic enzymes and azathioprine-induced myelosuppression in 1,419 chinese patients: a retrospective study. Front Pharmacol. 2021;12: 672769.

26. Relling MV, Schwab M, Whirl-Carrillo M, et al. Clinical pharmacogenetics implementation consortium guideline for thiopurine dosing based on TPMT and NUDT15 genotypes: 2018 update. Clin Pharmacol Ther. 2019;105(5):1095-105.

27. Stanulla M, Schaeffeler E, Möricke A, et al. Hepatic sinusoidal obstruction syndrome and short-term application of 6-thioguanine in pediatric acute lymphoblastic leukemia. Leukemia. 2021;35(9):2650-7.

28. Bayoumy AB, Mulder CJJ, Loganayagam A, et al. The relationship between thiopurine $S$-methyltransferase genotype/phenotype and 6-thioguanine nucleotide levels in 316 patients with inflammatory bowel disease on 6-thioguanine. Ther Drug Monit. 2021. https://doi.org/10.1097/FTD.0000000000000869.

29. Jharap B, de Boer N, Vos R, et al. Biotransformation of 6-thioguanine in inflammatory bowel disease patients: a comparison of oral and intravenous administration of 6-thioguanine. Br J Pharmacol. 2011;163(4):722-31.

30. Lennard L, Davies HA, Lilleyman JS. Is 6-thioguanine more appropriate than 6-mercaptopurine for children with acute lymphoblastic leukaemia? Br J Cancer. 1993;68(1):186-90. 
31. Larsen RH, Hjalgrim LL, Grell K, et al. Pharmacokinetics of tablet and liquid formulations of oral 6-mercaptopurine in children with acute lymphoblastic leukemia. Cancer Chemother Pharmacol. 2020;86(1):25-32.

32. Derijks LJ, Gilissen LP, Engels LG, et al. Pharmacokinetics of 6-thioguanine in patients with inflammatory bowel disease. Ther Drug Monit. 2006;28(1):45-50.

33. Huskisson EC. Azathioprine. Clin Rheum Dis. 1984;10(2):325-32.

34. Estevinho MM, Afonso J, Rosa I, et al. A systematic review and meta-analysis of 6-thioguanine nucleotide levels and clinical remission in inflammatory bowel disease. J Crohns Colitis. 2017;11(11):1381-92.

35. Sousa P, Estevinho MM, Dias CC, et al. Thiopurines' metabolites and drug toxicity: a meta-analysis. J Clin Med. 2020;9(7):2216.

36. Lancaster DL, Patel N, Lennard L, Lilleyman JS. 6-Thioguanine in children with acute lymphoblastic leukaemia: influence of food on parent drug pharmacokinetics and 6-thioguanine nucleotide concentrations. Br J Clin Pharmacol. 2001;51(6):531-9.

37. de Lemos ML, Hamata L, Jennings S, Leduc T. Interaction between mercaptopurine and milk. J Oncol Pharm Pract. 2007;13(4):237-40.

38. Burton NK, Barnett MJ, Aherne GW, Evans J, Douglas I, Lister TA. The effect of food on the oral administration of 6-mercaptopurine. Cancer Chemother Pharmacol. 1986;18(1):90-1.

39. Sparrow MP, Hande SA, Friedman S, et al. Allopurinol safely and effectively optimizes tioguanine metabolites in inflammatory bowel disease patients not responding to azathioprine and mercaptopurine. Aliment Pharmacol Ther. 2005;22(5):441-6.

40. Blaker PA, Arenas-Hernandez M, Smith MA, et al. Mechanism of allopurinol induced TPMT inhibition. Biochem Pharmacol. 2013;86(4):539-47.

41. Stockert AL, Stechschulte M. Allopurinol to Febuxostat: how far have we come? Clin Med Insights Ther. 2010;2: CMT.S6286.

42. Logan JK, Yapa SWS, Harinstein L, et al. Drug interaction between febuxostat and thiopurine antimetabolites: a review of the FDA adverse event reporting system and medical literature. Pharmacotherapy. 2020;40(2):125-32.

43. Szumlanski CL, Weinshilboum RM. Sulphasalazine inhibition of thiopurine methyltransferase: possible mechanism for interaction with 6-mercaptopurine and azathioprine. Br J Clin Pharmacol. 1995;39(4):456-9.

44. Lewis LD, Benin A, Szumlanski CL, et al. Olsalazine and 6-mercaptopurine-related bone marrow suppression: a possible drugdrug interaction. Clin Pharmacol Ther. 1997;62(4):464-75.

45. Tack GJ, Waayenberg P, de Boer NK. Beneficial pharmacological interaction between thiopurine and mesalazine - never change a winning team. J Crohns Colitis. 2014;8(12):1743-4.

46. Lowry PW, Franklin CL, Weaver AL, et al. Leucopenia resulting from a drug interaction between azathioprine or 6-mercaptopurine and mesalamine, sulphasalazine, or balsalazide. Gut. 2001;49(5):656-64.

47. Hande S, Wilson-Rich N, Bousvaros A, et al. 5-Aminosalicylate therapy is associated with higher 6-thioguanine levels in adults and children with inflammatory bowel disease in remission on 6-mercaptopurine or azathioprine. Inflamm Bowel Dis. 2006;12(4):251-7.

48. Gilissen LP, Bierau J, Derijks LJ, et al. The pharmacokinetic effect of discontinuation of mesalazine on mercaptopurine metabolite levels in inflammatory bowel disease patients. Aliment Pharmacol Ther. 2005;22(7):605-11.

49. Dewit O, Vanheuverzwyn R, Desager JP, Horsmans Y. Interaction between azathioprine and aminosalicylates: an in vivo study in patients with Crohn's disease. Aliment Pharmacol Ther. 2002;16(1):79-85.
50. de Boer NK, Wong DR, Jharap B, et al. Dose-dependent influence of 5-aminosalicylates on thiopurine metabolism. Am J Gastroenterol. 2007;102(12):2747-53.

51. Morikubo H, Kobayashi T, Ozaki R, et al. Differential effects of mesalazine formulations on thiopurine metabolism through thiopurine S-methyltransferase inhibition. J Gastroenterol Hepatol. 2021;36(8):2116-24.

52. Takahashi K, Bamba S, Morita Y, et al. pH-Dependent 5-aminosalicylates releasing preparations do not affect thiopurine metabolism. Digestion. 2019;100(4):238-46.

53. Dilger K, Schaeffeler E, Lukas M, et al. Monitoring of thiopurine methyltransferase activity in postsurgical patients with Crohn's disease during 1 year of treatment with azathioprine or mesalazine. Ther Drug Monit. 2007;29(1):1-5.

54. Xin H-W, Fischer C, Schwab M, Klotz U. Thiopurine S-methyltransferase as a target for drug interactions. Eur J Clin Pharmacol. 2005;61(5):395-8.

55. Lysaa RA, Giverhaug T, Libæk Wold H, Aarbakke J. Inhibition of human thiopurine methyltransferase by furosemide, bendroflumethiazide and trichlormethiazide. Eur J Clin Pharmacol. 1996;49(5):393-6.

56. Klemetsdal B, Straume B, Wist E, Aarbakke J. Identification of factors regulating thiopurine methyltransferase activity in a Norwegian population. Eur J Clin Pharmacol. 1993;44(2):147-52.

57. Hindorf U, Lindqvist $M$, Peterson $C$, et al. Pharmacogenetics during standardised initiation of thiopurine treatment in inflammatory bowel disease. Gut. 2006;55(10):1423-31.

58. Peyrin-Biroulet L, Cadranel JF, Nousbaum JB, et al. Interaction of ribavirin with azathioprine metabolism potentially induces myelosuppression. Aliment Pharmacol Ther. 2008;28(8):984-93.

59. Movva R, Lobb M, Oc P, Florin THJ, Duley JA, Oancea I. Microbial metabolism of thiopurines: a method to measure thioguanine nucleotides. J Microbiol Methods. 2016;128:102-7.

60. Oancea I, Movva R, Das I, et al. Colonic microbiota can promote rapid local improvement of murine colitis by thioguanine independently of $\mathrm{T}$ lymphocytes and host metabolism. Gut. 2017;66(1):59-69.

61. Florin THJ, Wright JD, Jambhrunkar SD, Henman MG, Popat A. A well-tolerated and rapidly acting thiopurine for IBD? Drug Discov Today. 2019;24(1):37-41.

62. Yang Y, Zhou S, Ouyang R, et al. Improvement in the anticancer activity of 6-mercaptopurine via combination with bismuth(III). Chem Pharm Bull (Tokyo). 2016;64(11):1539-45.

63. Wang JR, Yu X, Zhou C, et al. Improving the dissolution and bioavailability of 6-mercaptopurine via co-crystallization with isonicotinamide. Bioorg Med Chem Lett. 2015;25(5):1036-9.

64. Xu L-L, Chen J-M, Yan Y, Lu T-B. Improving the solubility of 6-mercaptopurine via cocrystals and salts. Cryst Growth Des. 2012;12(12):6004-11.

65. Yao J, Chen J-M, Xu Y-B, Lu T-B. Enhancing the solubility of 6-mercaptopurine by formation of ionic cocrystal with zinc trifluoromethanesulfonate: single-crystal-to-single-crystal transformation. Cryst Growth Des. 2014;14(10):5019-25.

66. Lu X, Xie Y, Wang F, Boulanouar I, Gallais A. Application and analysis of 6-mercaptopurine nanomedicine in the treatment of leukemia. J Nanosci Nanotechnol. 2021;21(2):1001-7.

67. Sierpe R, Noyong M, Simon U, et al. Construction of 6-thioguanine and 6-mercaptopurine carriers based on $\beta$ cyclodextrins and gold nanoparticles. Carbohydr Polym. 2017;177:22-31.

68. Rajashekaraiah R, Kumar PR, Prakash N, et al. Anticancer efficacy of 6-thioguanine loaded chitosan nanoparticles with or without curcumin. Int J Biol Macromol. 2020;148:704-14.

69. Qiu J, Cheng R, Zhang J, et al. Glutathione-sensitive hyaluronic acid-mercaptopurine prodrug linked via carbonyl vinyl sulfide: a 
robust and CD44-targeted nanomedicine for leukemia. Biomacromol. 2017;18(10):3207-14.

70. Govindappa PK, Joladarashi D, Hallur RLS, Sanganal JS, Phani AR. Toxicity evaluation of 6-mercaptopurine-Chitosan nanoparticles in rats. Saudi Pharm J. 2020;28(1):147-54.

71. Wan Y, Bu Y, Liu J, et al. PH and reduction-activated polymeric prodrug nanoparticles based on a 6-thioguanine-dialdehyde sodium alginate conjugate for enhanced intracellular drug release in leukemia. Polym Chem. 2018;9:3415-24.

72. Kumar GP, Sanganal JS, Phani AR, et al. Anti-cancerous efficacy and pharmacokinetics of 6-mercaptopurine loaded chitosan nanoparticles. Pharmacol Res. 2015;100:47-57.

73. Chatterjee M, Jaiswal N, Hens A, Mahata N, Chanda N. Development of 6-thioguanine conjugated PLGA nanoparticles through thioester bond formation: benefits of electrospray mediated drug encapsulation and sustained release in cancer therapeutic applications. Mater Sci Eng C. 2020;114: 111029.

74. Ahmed A, Badr Y, Shouman S, Sliem M. Improvement of 6 mercaptopurine efficiency by encapsulated in chitosan nanoparticles. Arab J Nucl Sci Appl. 2018;51:1-7.

75. Aghevlian S, Yousefi R, Faghihi R, et al. The improvement of anti-proliferation activity against breast cancer cell line of thioguanine by gold nanoparticles. Med Chem Res. 2013;22(1):303-11.

76. Dorniani D, Hussein MZB, Kura AU, Fakurazi S, Shaari AH, Ahmad Z. Preparation and characterization of 6-mercaptopurinecoated magnetite nanoparticles as a drug delivery system. Drug Des Dev Ther. 2013;7:1015-26.

77. Sleightholm L, Zambre A, Chanda N, Afrasiabi Z, Katti K, Kannan R. New nanomedicine approaches using gold-thioguanine nanoconjugates as metallo-ligands. Inorg Chim Acta. 2011;372(1):333-9.

78. Bangham AD, Horne RW. Negative staining of phospholipids and their structural modification by surface-active agents as observed in the electron microscope. J Mol Biol. 1964;8(5):660-IN610.

79. Torchilin VP. Recent advances with liposomes as pharmaceutical carriers. Nat Rev Drug Discov. 2005;4(2):145-60.

80. Bulbake U, Doppalapudi S, Kommineni N, Khan W. Liposomal formulations in clinical use: an updated review. Pharmaceutics. 2017;9(2):12.

81. Almeida B, Nag OK, Rogers KE, Delehanty JB. Recent progress in bioconjugation strategies for liposome-mediated drug delivery. Molecules. 2020;25(23):5672.

82. Tsujii K, Sunamoto J, Fendler JH. Improved entrapment of drugs in modified liposomes. Life Sci. 1976;19(11):1743-9.

83. Kano K, Fendler JH. Enhanced uptake of drugs in liposomes: use of labile vitamin B12 complexes of 6-mercaptopurine and 8-azaguanine. Life Sci. 1977;20(10):1729-34.

84. Gulati M, Grover M, Singh M, Singh S. Study of azathioprine encapsulation into liposomes. J Microencapsul. 1998;15(4):485-94.

85. Foradada M, Estelrich J. Encapsulation of thioguanine in liposomes. Int J Pharm. 1995;124(2):261-9.

86. Casals E, Gallardo M, Estelrich J. Factors influencing the encapsulation of thioguanine in DRV liposomes. Int J Pharm. 1996;143(2):171-7.

87. Agrawal V, Paul MK, Mukhopadhyay AK. 6-mercaptopurine and daunorubicin double drug liposomes-preparation, drug-drug interaction and characterization. J Liposome Res. 2005;15(3-4):141-55.

88. Umrethia M, Ghosh PK, Majithya R, Murthy RSR. 6-Mercaptopurine (6-MP) entrapped stealth liposomes for improvement of leukemic treatment without hepatotoxicity and nephrotoxicity. Cancer Invest. 2007;25(2):117-23.
89. Taneja D, Namdeo A, Mishra PR, Khopade AJ, Jain NK. High-entrapment liposomes for 6-mercaptopurine-a prodrug approach. Drug Dev Ind Pharm. 2000;26(12):1315-9.

90. Kesisoglou F, Zhou SY, Niemiec S, Lee JW, Zimmermann EM, Fleisher D. Liposomal formulations of inflammatory bowel disease drugs: local versus systemic drug delivery in a rat model. Pharm Res. 2005;22(8):1320-30.

91. Beltrán-Gracia E, López-Camacho A, Higuera-Ciapara I, Velázquez-Fernández JB, Vallejo-Cardona AA. Nanomedicine review: clinical developments in liposomal applications. Cancer Nanotechnol. 2019;10(1):11.

92. Suhasini K, Sanganal J, Phani A, et al. Synthesis, characterisation of azathioprine loaded chitosan based nanoparticles. Global J Res Anal. 2012;3:245-7.

93. Mohammed MA, Syeda JTM, Wasan KM, Wasan EK. An overview of chitosan nanoparticles and its application in non-parenteral drug delivery. Pharmaceutics. 2017;9(4):53.

94. Arunkumar PD, Saravanan M. Magnetic and compartmental targeting of azathioprine using gelatin microspheres: formulation, physicochemical characterization and in vitro release studies. J Appl Pharm Sci. 2013;3(10):17.

95. Mody VV, Siwale R, Singh A, Mody HR. Introduction to metallic nanoparticles. J Pharm Bioallied Sci. 2010;2(4):282-9.

96. Podsiadlo P, Sinani VA, Bahng JH, Kam NW, Lee J, Kotov NA. Gold nanoparticles enhance the anti-leukemia action of a 6-mercaptopurine chemotherapeutic agent. Langmuir. 2008;24(2):568-74.

97. Giljohann DA, Seferos DS, Daniel WL, Massich MD, Patel PC, Mirkin CA. Gold nanoparticles for biology and medicine. Angew Chem Int Ed Engl. 2010;49(19):3280-94.

98. Chen N, Wang H, Huang Q, et al. Long-term effects of nanoparticles on nutrition and metabolism. Small. 2014;10(18):3603-11.

99. Zins BJ, Sandborn WJ, McKinney JA, et al. A dose-ranging study of azathioprine pharmacokinetics after single-dose administration of a delayed-release oral formulation. J Clin Pharmacol. 1997;37(1):38-46.

100. Nagendra R, Pai RS, Singh G. Design and optimization of novel in situ gel of mercaptopurine for sustained drug delivery. Braz $\mathbf{J}$ Pharm Sci. 2014;50:107-19.

101. Van Os EC, Zins BJ, Sandborn WJ, et al. Azathioprine pharmacokinetics after intravenous, oral, delayed release oral and rectal foam administration. Gut. 1996;39(1):63-8.

102. Israeli E, Goldin E, Fishman S, et al. Oral administration of nonabsorbable delayed release 6-mercaptopurine is locally active in the gut, exerts a systemic immune effect and alleviates Crohn's disease with low rate of side effects: results of double blind Phase II clinical trial. Clin Exp Immunol. 2015;181(2):362-72.

103. Simsek M, Deben DS, Horjus CS, et al. Sustained effectiveness, safety and therapeutic drug monitoring of tioguanine in a cohort of 274 IBD patients intolerant for conventional therapies. Aliment Pharmacol Ther. 2019;50(1):54-65.

104. Bayoumy AB, van Liere E, Simsek M, et al. Efficacy, safety and drug survival of thioguanine as maintenance treatment for inflammatory bowel disease: a retrospective multi-centre study in the United Kingdom. BMC Gastroenterol. 2020;20(1):296.

105. Lautenschläger C, Schmidt C, Fischer D, Stallmach A. Drug delivery strategies in the therapy of inflammatory bowel disease. Adv Drug Deliv Rev. 2014;71:58-76.

106. Hua S. Orally administered liposomal formulations for colon targeted drug delivery. Front Pharmacol. 2014;5:138.

107. Florin T, Movva R, Begun J, Duley J, Oancea I, Cuív P. Colonic thioguanine pro-drug: investigation of microbiome and novel host metabolism. Gut Microbes. 2018;9(2):175-8. 
108. Bronk JR, Lister N, Shaw MI. Transport and metabolism of 6-thioguanine and 6-mercaptopurine in mouse small intestine. Clin Sci (Lond). 1988;74(6):629-38.

109. Houshmand M, Garello F, Circosta P, et al. Nanocarriers as magic bullets in the treatment of leukemia. Nanomaterials (Basel). 2020;10(2):276.

110. Halappanavar S, Vogel U, Wallin H, Yauk CL. Promise and peril in nanomedicine: the challenges and needs for integrated systems biology approaches to define health risk. Wiley Interdiscip Rev Nanomed Nanobiotechnol. 2018;10(1): e1465.

111. Pasut G. Grand challenges in nano-based drug delivery. Front Med Technol. 2019. https://doi.org/10.3389/fmedt.2019.00001.

112. Bosetti R. Cost-effectiveness of nanomedicine: the path to a future successful and dominant market? Nanomedicine. 2015;10(12):1851-3.

113. Kaur G, Hearn MTW, Bell TDM, Saito K. release kinetics of 6-mercaptopurine and 6-thioguanine from bioinspired corecrosslinked thymine functionalised polymeric micelles. Aust $\mathbf{J}$ Chem. 2013;66(8):952-8.

114. Moezi E, Mirzaei M. Graphene scaffold for tioguanine delivery: DFT approach. Lab Silico. 2021;2(1):25-9.

115. Mahdinia S, Hajali N, Zarifi K, Moradi Z, Alipourfard I. Delivery of tioguanine anticancer drug by Fe-doped fullerene cage: DFT evaluation of electronic and structural features. Comput Theor Chem. 2021;1204: 113401.

116. Mahboobi T, Zardoost MR, Toosi MR. Phosphorene and Na-, $\mathrm{Ca}-$, and $\mathrm{Fe}$-doped phosphorene as candidates for delivery of mercaptopurine and fluorouracil anticancer drugs. J Mol Model. 2020;26(10):269.

117. Zaboli M, Raissi H, Zaboli M. Investigation of nanotubes as the smart carriers for targeted delivery of mercaptopurine anticancer drug. J Biomol Struct Dyn. 2020:1-14

118. Abd El-Mageed HR, Abbas HS. Adsorption behavior of mercaptopurine and 6-thioguanine drugs on the $\mathrm{B}(12) \mathrm{N}(12), \mathrm{AlB}(11)$ $\mathrm{N}(12)$ and $\mathrm{GaB}(11) \mathrm{N}(12)$ nanoclusters, a comparative DFT study. J Biomol Struct Dyn. 2021:1-20

119. Zou Y, Mei D, Yuan J, et al. Preparation, characterization, pharmacokinetic, and therapeutic potential of novel 6-mercaptopurine-loaded oral nanomedicines for acute lymphoblastic leukemia. Int J Nanomedicine. 2021;16:1127-41.

120. Grabowska-Jadach I, Drozd M, Kulpińska D, Komendacka K, Pietrzak M. Modification of fluorescent nanocrystals with 6-thioguanine: monitoring of drug delivery. Appl Nanosci. 2020;10(1):83-93. 